\title{
Investigation of Absorbed Dose Rate in Air by a Car-borne Survey in Namie
}

\section{Town, Fukushima Prefecture}

Chanis Pornnumpa, Kazuki Iwaoka, Naofumi Akata, Masahiro Hosoda,

Atsuyuki Sorimachi and Shinji Tokonami (Please see page 115)
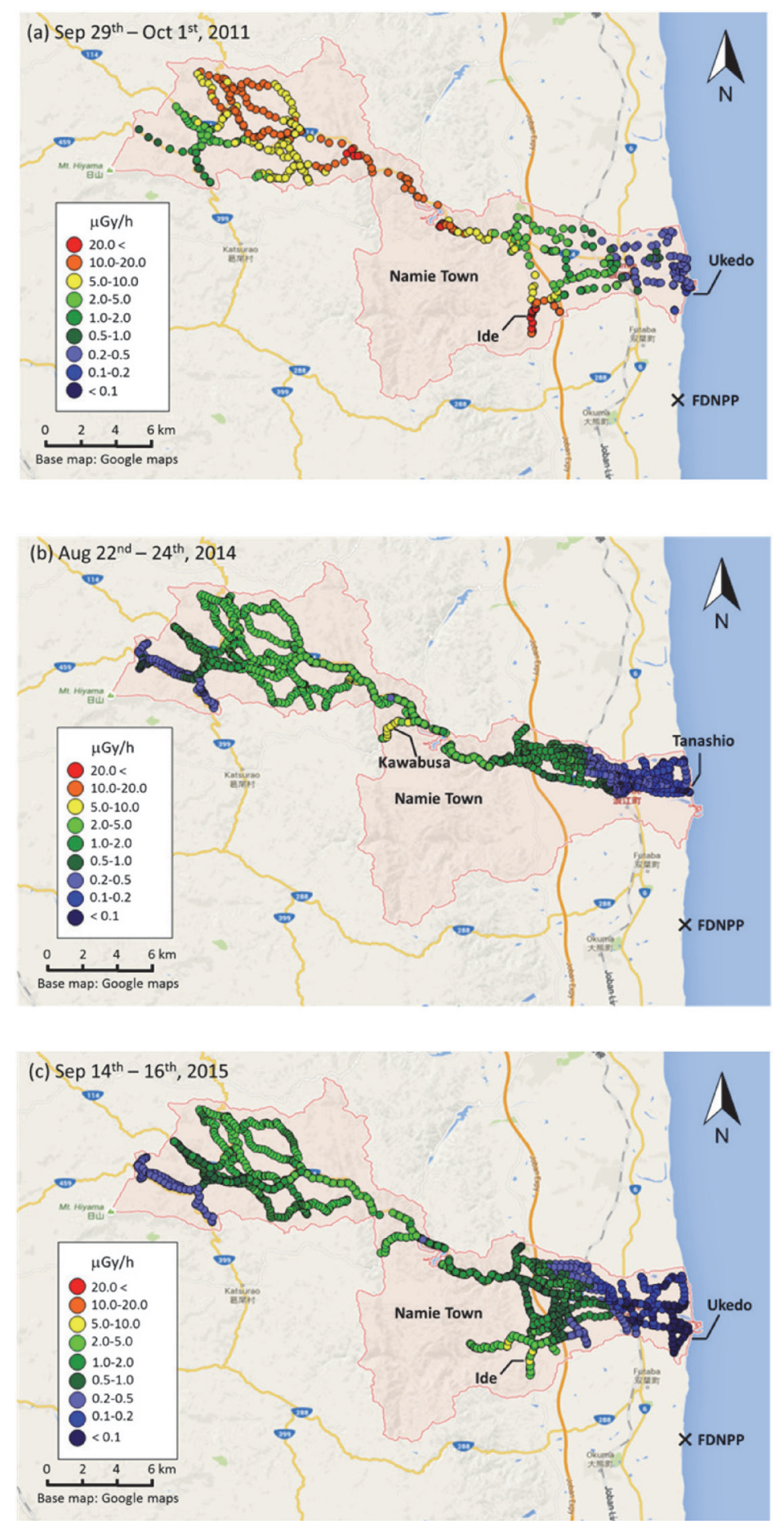

Fig. 3 (a) Distribution of the absorbed dose rate in air on September $29^{\text {th }}$-October $1^{\text {st }}$, 2011. (b) Distribution of the absorbed dose rate in air on August $22^{\text {nd }}-24^{\text {th }}, 2014$. (c) Distribution of the absorbed dose rate in air on September $14^{\text {th }}-16^{\text {th }}, 2015$. Dot maps were made by Surfer software and Google maps. 